\title{
Investigating Open Innovation and Interorganizational Networks in the IT Industry: The Case of Standard Software Customization
}

\author{
Karlheinz Kautz ${ }^{1}$, Deborah Bunker ${ }^{2}$, Sameen M. Rab $^{1}$, and Michael Sinnet ${ }^{1}$ \\ ${ }^{1}$ Informatics, Copenhagen Business School, Howitzvej 60, DK-2000 Frederiksberg, Denmark \\ Karl.Kautz@cbs.dk, Smr@kmd.dk, Michael@Sinnet.dk \\ ${ }^{2}$ Faculty of Economics and Business, University of Sydney, NSW2006, Australia \\ Deborah. Bunkeresydney . edu. au
}

\begin{abstract}
This research presents and analyzes an empirically grounded account of a new trend, open innovation, in the IT industry. The case depicts another new trend, innovation through customization of standard software as a business model, and we investigate the open innovation activities of an interorganizational network which consists of a small customizing company, a large global software producer, and other companies involved in the innovation process. We contribute to the development of a theory of open IT innovation with a theoretical framework that integrates formally separate aspects of open innovation and interorganizational networks. We extend the literature on open innovation by broadening the view from one focal firm to the relations in a network of companies that mutually contribute to innovation which occur in the different companies. Our research underlines the importance of balanced formal and informal relations, and coopetive and opportunistic behavior for the open innovation process.
\end{abstract}

Keywords: Open innovation, interorganizational networks, software customization.

\section{Introduction}

The research presented here investigates a new trend in the information technology industry. Open innovation is a novel way to create innovation where organizations open their innovation processes and cooperate with others to develop new products and services (Chesbrough 2003; Kautz et al. 2009). However, beyond work on open source development (see, for example, West and Gallagher 2005) and in extension of these efforts, Ågerfalk and Fitzgerald's (2008) research on open sourcing-they study from an individual psychological contract perspective the use of the open source development model where commercial companies and open source communities collaborate on the development of software innovations-little insight on open IT innovation exists. We study open innovation by taking another future trend into account, namely innovation through customization of standard software as a business model (Pollock et al. 2003). 
Interorganizational relationships and networks are both decisive for open innovation and software customization. The latter has mostly been described in the literature as a general development activity which takes place within the organization that has developed the software. There is another view that looks at customization as a specialized business activity performed by an independent business: the software customizer. This view implies some interaction in interorganizational networks between the customizer and the developer to effectively customize the software (Pollock et al. 2003).

Open innovation takes place in interorganizational networks (Vanhaverbeke 2006). Feller et al. (2009) provide a categorization of interorganizational relationships in open innovation based on whether these relationships are mediated or direct, and whether they seek to exchange intellectual property or innovation capability. On this basis, they call for more research that takes an interorganizational perspective on facilitating open innovation into account.

On this background, we empirically investigate the open innovation activities of an interorganizational network which consists of a small customizing company, a large global software producer, and other companies involved in the innovation process. Our research question, then, is how does open innovation take place in interorganizational networks in the IT industry?

Table 1. A Framework for Open Innovation in Interorganizational Networks: Key Concepts

\begin{tabular}{|c|c|}
\hline Open Innovation & Interorganizational Networks \\
\hline $\begin{array}{l}\text { Idea and Knowledge Flow } \\
\text { Knowledge Sharing Opportunities } \\
\text { Product Access and Flow } \\
\text { Adaptable Development Context } \\
\text { Active Partner Search } \\
\text { Inducements }\end{array}$ & 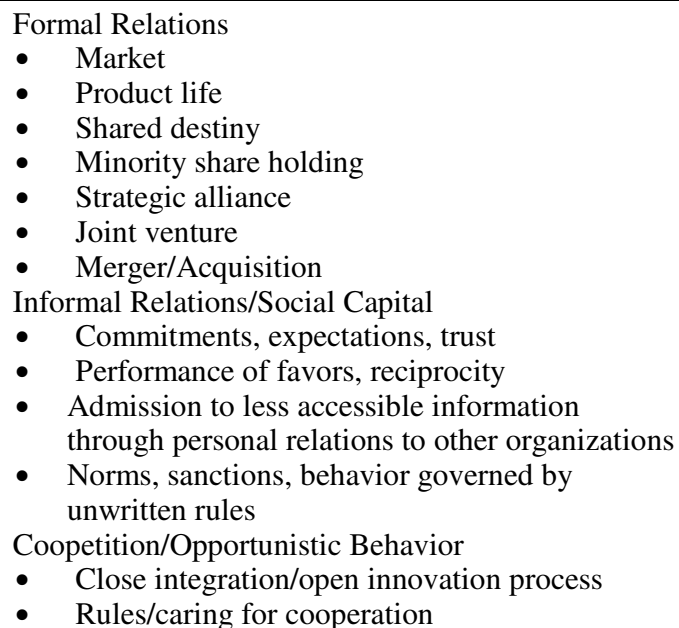 \\
\hline
\end{tabular}

The remainder of the article is structured as follows: in the next section we provide the theoretical background for our research and present a theoretical framework which integrates concepts of open innovation with concepts of interorganizational networks (summarized in Table 1) to study standard software customization as an instance of open innovation in our case setting. We then introduce our interpretive case study research approach and the case description. This is followed by our case analysis and 
the presentation and discussion of our findings. We finish with a summary of our contributions and some conclusions.

\section{Theoretical Background}

\subsection{Open Innovation}

Open innovation (Chesbrough 2003) means that valuable ideas can come from inside or outside a company and can go to the market from inside and outside the company. Organizations committing to open innovation view the outside world as a source of inspiration and accept the strategic potential of letting other organizations contribute to the innovation process. Grassman and Enkel (2004) distinguish between an outside-in process where external knowledge and technologies are acquired from outside a company, but the locus of innovation is within the company, an inside-out process where unused knowledge and technologies are introduced to the market, but mostly exploited inside the company, and a coupled process where these two processes are joined and the company works in alliance with others in various forms of cooperation; the locus of innovation lies both inside and outside the company. Heavy exchange of ideas and easy access to products is a prerequisite for open innovation (Vanhaverbeke and Cloodt 2006).

Open innovation is linked to openness with regard to access to a product, but it is also an overall strategy to improve the conditions for companies, which contribute to the innovation process (Vanhaverbeke and Cloodt 2006); this can mean to provide inducements such as capital for start-up companies that want to further develop their products and might function as laboratories for large organizational sponsors in the innovation process.

When engaging in open innovation, companies have to understand their role with regard to other involved parties (Vanhaverbeke and Cloodt 2006). This includes searching for new partners, providing opportunities for innovators to effectively share their knowledge and their ideas (Vanhaverbeke and Cloodt 2006), for example, knowledge sharing forums in which the developers use each other as mutual inspiration to support the creation of innovations (von Hippel 2005), and providing an appropriate development context, for example, suitable development tools and a product of high quality with a flexible product architecture, as well as providing further incentives in the form of new markets (Chesbrough 2003) where the customized solutions attract attention, but also create additional business value for the original product.

Nursing and steering an open interorganizational innovation network is significant to develop or use innovations (Vanhaverbeke and Cloodt 2006). Interorganizational relations facilitate organizations' capabilities and willingness to open their innovation process and let innovation happen across organizational boundaries (Simard and West 2006). The composition of the network has an impact on the innovative processes (Vanhaverbeke 2006). It is important not to be satisfied with tying together some established interorganizational cooperation partners, but to build up a network that consists of many broad relationships instead of a network with a few and deep relations (Simard and West 2006). This approach utilizes innovative opportunities better as the generation of ideas becomes much more unpredictable. But open 
innovation networks can take many forms. Organizations can participate in the research and development of an innovative product, resell the product, promote the product, or build upon the existing product (Chesbrough 2006). The knowledge and product flow between organizations in open innovation does not necessarily have to occur in the unrestricted public domain, but can take place in hierarchical relationships (Feller et al. 2009) or on a dyadic level (Vanhaverbeke and Cloodt 2006). The advantages of letting other organizations contribute to the development of new products mostly outweigh the difficulties of coordinating interorganizational processes (Chesbrough 2003).

\subsection{Interorganizational Networks}

Interorganizational networks are a specific type of relation that binds organizations closely together through communication, interaction, and cooperation (Harland 1996; Håkasson and Snehota 1995). These features provide a competitive advantage that could not have been achieved by organizations on their own (Dyer and Singh 1998). A network reduces the transaction costs for the exchange of information, minimizes uncertainty, and limits opportunistic behavior (Williamson 1991).

Interorganizational relations depend on the degree of formal cooperation between the organizations (Harland 1996) where organizations may have no shared objectives, deal with each other on the market, and communicate through purchase orders, to situations where organizations merge or where one organization acquires or influences others through joint ventures, strategic alliances, and minority shareholdings. Shared destiny and product life relationships see partners sharing their vision and cooperating either with regard to the organizations as a whole or with regard to individual products.

When problems arise, formal contracts are often inhibiting; informal and emergent approaches are often more usable, but organizations that know each other well and have mutual trust achieve the most effective outcomes (Håkansson and Snehota 1995). Coleman (1988) has defined the concept of social capital which contributes to an organization's competitive capacities. Interorganizational networks consist of a social structure of relations of employees across the different organizations. This consists of three elements: (1) commitments, expectations, and trust, which relate to the performance of favors and services without payment based on reciprocity, (2) information channels, which provide access to less accessible information through personal relations to trusted employees in other organizations, and (3) norms and sanctions, which are the unwritten rules which exist between people and which govern how they act and behave.

An important aspect in such networks is relations that can take a form where organizations might simultaneously cooperate and compete with each other, called coopetition (Ganguli 2007). The objective of coopetive relations is to achieve a joint competitive advantage by competing while at the same time jointly striving for better quality in other areas. The informal knowledge exchanged in these relationships can often benefit coopetive partners; however, such relationships are difficult to manage and control and invite opportunistic behavior (von Hippel 1987). Opportunistic behavior can be reduced through close integration and nursing the cooperation between partners. Defining the scope and the rules for innovation and cooperation is 
one way to achieve this; another way is opening up the innovation process and letting interested parties contribute to this process.

\subsection{Standard Software Customization}

Standard software has existed since the 1960s (Sawyer 2000), with the aim of creating a common comprehensive business software solution which can be implemented for a broad range of businesses. Standard software hardly ever satisfies all business needs (Scott and Kaindl 2000) and organizations want to adapt or customize the standard software for their own needs (Simard and West 2006).

Light (2001, p. 416) argues that

Customization is meant to describe changes or additions to the functionality available in the standard software. It does not refer to the switching on and off of functionality that is part of the blueprint of the software, sometimes referred to as software configuration.

Software customization as a creative task goes beyond adjusting pre-defined settings; while including simple configuration practices such as the creation of reports, amendment of existing reports and/or displays, automation of existing processes, a greater effort is expended in changing existing functionality and addition of functionality (Kuitunen et al. 2005).

In this research, we consider customization as a specialized business activity performed by an independent business (Pollock et al. 2003) which is distinct from tailoring and modifying information systems through users (Germonprez et al. 2007). Software customization businesses can then be categorized according to two parameters (Kuitunen et al. 2005): (1) how tailored or standardized are a software company's products and services (tailored offerings versus standardized offerings) and (2) are the company's earnings primarily based on the sales of products or performance of services (product-based business versus service based business)?

\section{Research Approach}

Our research follows the approach of engaged scholarship (Van de Ven 2007), a participative form of research for seeking advice and perspectives of key stakeholders in order to understand and theorize about a complex problem. Given the limited research literature concerning our topic, our investigation is based on an exploratory, qualitative, single case study (Creswell 2003) of open innovation activities in an interorganizational network that consists of the small Danish software company Alpha, which customizes a software product, the large global software company Zeta, the producer of the original software product, and other companies involved.

Our research approach is inspired by Eisenhardt (1989) and Walsham (1995), who stress that in all types of research, including case study research, theory is important as an initial guide to data collection, during the iterative process of data analysis, and as a final product of the research. While it is often stated that it is not possible to generalize and certainly not to theorize from a single case study, it is possible to generalize case study findings among others in the form of a contribution of rich 
insight (Walsham 1995). We thus used our theoretical framework to guide our data collection and analysis in order to contribute to the existing body of knowledge with rich insight about open innovation in interorganizational networks.

The empirical data for the case study was collected in semi-structured, open-ended interviews conducted by a team of two researchers. The team focused on Alpha and performed six interviews with its founders and key personnel, covering more than half of the organization's staff, and with their partner account manager at Zeta. The interview data was supplemented with publicly available and internal company documents, especially about Zeta's partnership program. The interviews were taperecorded and transcribed. Subsequently the data was coded independently by the two researchers. The few differences in the researchers' conceptions were discussed and resolved in collaboration with a third researcher. To move from surface observations toward theory building and from description to explanation, a detailed narrative of the case was written. In a narrative theory, the story builds a conceptual model where the story provides a progress or sequence of events (Van de Ven 2007) which serves as an additional frame of reference for the further analysis and interpretation of the data (Fincham 2002). In this process, the third and fourth members of the team acted as facilitators and carefully scrutinized the narrative. The combination of interpretation and collaboration between the four researchers with different levels of involvement brought interpretive rigor to the project.

\section{The Case}

In this section, we describe the case setting and take as a point of origin company Alpha. As the basis for the subsequent analysis, we describe how relations were formed, changed, and disbanded in the different phases which the organization went through. We identified seven such phases and our description is a narrative in seven acts (see Table 2).

Table 2. The Seven Phases of the Case Narrative

\begin{tabular}{|l|l|l|l|l|l|l|}
\hline Freelance & Launch & Partnership & $\begin{array}{c}\text { Product } \\
\text { Development }\end{array}$ & Growth & Outsourcing & Merger \\
\hline
\end{tabular}

\subsection{Freelance}

Alpha has its origins in the company Omega. Omega, established early in 2005 as a consultancy company, focuses on a CRM (customer relationship management) product developed in 2004 by the software producer Zeta. Omega's founders are former Zeta product managers. Omega is a Zeta partner and resells Zeta's CRM product, but to do this they must have the technical skills for implementing the product. As they lack these skills in the summer 2005, Omega hires a freelance IT professional for technical support and product configuration. Subsequently, the business develops very quickly and another freelancer is hired. In this phase, Omega and the freelancers have an informal relationship without any direct payment for the work. Assignments are largely related to system configuration and customer-specific adjustments where some customers wish to import data from other systems into the CRM. 


\subsection{Launch}

In the fall of 2005, Alpha is created by the freelancers focusing on consultancy tasks and adjusting the CRM for their customers, obtained through Omega's contacts. Importing customer data for different customers is their main focus with Omega as their strategic partner.

This phase is dominated by informal guidelines and development methods. Low cost solutions are the order of the day and the informal agreements create stability which provides Alpha with a firm base for their first standard product offering. As the assignments from different customers become similar, the founders of Alpha decide to develop a standardized solution, which Omega resells to their customers and which creates most of Alpha's initial earnings.

\subsection{Partnership}

The product satisfies the certification requirements in Zeta's partnership program. In the beginning of 2006, Alpha becomes a certified partner, as an independent company officially offering Zeta-based IT-services, products, and know-how. In April 2006, Alpha becomes a Gold Zeta partner, receiving more attention, support, licenses and knowledge from Zeta. They can also preview, experiment with, and test the beta versions of products much earlier. Zeta sets up the relationship through a Partner Account Manager, but this limits Alpha's access to Zeta's technical knowledge which they need to adapt the CRM product.

Alpha feels that the formal communication with Zeta is longwinded, so they look for new possibilities to get information about the CRM product. The Omega founders create a number of informal relations between Alpha and some Zeta developers, where those involved support each other by mutually exchanging information on the CRM product. These informal relations are advantageous for Alpha as they no longer need to utilize Zeta's communication channels to get information on their products, thus enhancing the relationship with Zeta.

In June 2006, Alpha appears at the annual Zeta conference in the United States to present their standardized product to Zeta partners. This is the first of many international conferences Alpha uses to strengthen its network and to develop partnerships with other Zeta partners. The new partnerships consist primarily of distribution contracts with existing CRM vendors who see an advantage in including Alpha's solutions in their portfolio. In the fall of 2006, Alpha succeeds in interesting several local Danish CRM vendors which increasingly take over contact with potential customers. This leads to the end of Omega's role as the link between Alpha and new partners. Alpha now takes over contact with these partners and, although customers still can buy Alpha's products from the company's web site, Alpha chooses to change their focus from customers to distribution partners who thus become links in Alpha's network.

\subsection{Product Development}

The new partner focus is an opportunity for Alpha to sell their products to a larger range of customers. Until the end of 2006, Alpha's work assignments consist both of consultancy services and the development of their own standardized solutions. The 
success of their first product leads to an understanding of the large potential in dedicated product development and standardized solutions. A number of new off-theshelf products are developed of which both the new version of their first product and a system to import business data from the yellow pages achieve Zeta certification. During 2007, the company develops a further three products based on the CRM system. All three solutions meet the demands of a broad user group and fill gaps in the original CRM product.

Lacking legal protection of their ideas, however, Alpha is forced to continuously develop new products, among others yet another new version of their first product, their major product.

\subsection{Growth}

As Alpha products are limited in lifespan, in January 2007, Alpha starts to develop more products leading to an increased need for resources to supply technical products with user-friendly descriptions that support their positive reputation.

To further improve this reputation, over the next few months Alpha hires a sales and promotions person as well as a couple of developers to take care of their home page-used to distribute promotion materials, offer products and handle customer enquiries-as well as of their important first product. In September 2007, the founders decide to headhunt their Zeta partner account manager, who has been very enthusiastic about the company. He is employed as a sales manager, a business domain so far given low priority, and assumes an important role bringing both knowledge about the industry sector and more of Zeta's contacts and partners with him.

\subsection{Outsourcing}

In the fall of 2007, more international companies start to show interest in Alpha's primary product. Alpha chooses to cooperate with the largest CRM vendor in the United States. Delta, and launches a specific Delta product version. As Delta insists on using its own software testers in India, this collaboration becomes Alpha's first step toward outsourcing. The positive experience with these IT professionals results in the decision to continue to use their services instead of performing tests internally.

In November 2007, Alpha contacts the Danish company Gamma, which specializes in outsourcing of IT related work tasks. Gamma offers them a solution where three highly educated developers from Pakistan with CRM experience and low salaries are assigned to product development. Despite some challenges related to the different time zones, culture, and communication, Alpha's founders state that the decision to outsource has been favorable for the company.

At first, Alpha experiences problems with the further development of software without technical documentation, which was not an issue when developers had the necessary knowledge for this task. This leads to an effort to help the foreign developers understand and adopt the way Alpha customizes Zeta's CRM. At the same time, all code developed abroad is reviewed by Danish developers to ensure that the developers in Pakistan follow Alpha's guidelines. A focus is put on documentation and governance to ensure development quality. 


\subsection{Merger}

Finally, in spite of a historically happy relationship, in March 2008, Alpha and Omega opt to merge. Alpha sees an advantage in the merger as they want to increase their market share and extend their network and the merger provides access to more than 100 new partners worldwide.

\section{Analysis and Discussion}

The case description provides highlights of a company's successful business model of customizing standard software in an open innovation context by closing gaps in an original CRM product through additional functionality. Alpha has moved from tailoring individual solutions for customers to the development of standardized, customized products (Kuitunen et al. 2005). Their primary product represents a classic functional extension of the original CRM product. The other products either fall in this category or are process automations or amendments of existing reports (Light 2001).

Since the early 1990s, Zeta has focused on opening up their innovation processes. Valuable ideas and knowledge enter and leave the organization in the research and development stages where external companies contribute with competence, suggestions, and newly developed products. To gain rich insight about open innovation in our case setting, we focus on the relation between Alpha and Zeta on a dyadic level (Vanhaverbeke and Cloodt 2006).

We find an open innovation process where external knowledge and technologies are acquired from outside a company, and where internal knowledge and technologies are introduced to the outside. This is a coupled process; Gassman and Enkel (2004) put forward that the locus of innovation in such a case is often outside the company. We find that both focal companies innovate as a result of their mutual relationship; innovation takes place inside both companies and analogically outside of them as well.

The launch of Alpha is a direct consequence of the development and diffusion of Zeta's CRM product; Alpha can thus be considered a spin-off company. From its start, Alpha focused on this standard product. Through Omega's customer network, they got ideas for customizations and adjustments that were lacking in the original product. Omega's close relationship to Zeta contributed to that development knowledge from Zeta was shared with Alpha across Zeta's boundaries. This knowledge then contributed to Alpha's idea of building their first product. This had decisive influence on Alpha's certification as Gold Partner, which gave Alpha access to knowledge that is produced in Zeta's research process.

Yoo et al. (2008) classify open source innovation as a type of innovation network that is based on homogeneous knowledge sources and a distributed mode of control and coordination. Our case innovation network shows many of these traits, but we can also argue that Zeta is to a large extent controlling the network, thus showing traits of a centralized market with heterogeneous knowledge sources, or that Alpha much more independently follows its own path to innovation pointing toward a doubly distributed network with heterogeneous sources and distributed control. 
Feller et al. (2009) distinguish four types of interorganizational relationships in open innovation; these are solution hierarchy, a direct relation with a focus on intellectual property; solver market, a direct relation with a focus on innovation capabilities; solution brokerage, a mediated relation with a focus on intellectual property; and solver brokerage, a mediated relation with a focus on innovation capabilities. We find a complex mesh of multiple relations which cannot be categorized so neatly; both focal companies seek knowledge in hierarchical and market relations and brokers such as Omega provide knowledge of potential solvers and solutions.

As Alpha has detailed knowledge about the CRM product, they contribute with development ideas which they believe are important to be implemented in the original product. Alpha has promoted the idea that the CRM product should interact with other vendors' data base systems. Zeta is interested in these kinds of ideas and collects them through interviews with their partners, who in the research phase put their stamp on the future product.

Zeta has created forums where people who innovate their products can ask technical questions and extend their product knowledge. Zeta has an online forum for developers who customize their standard software. The online forum only plays a small role in Alpha's work, but it evinces Zeta's efforts to create an information flow between its own and external developers. In Alpha's case, the Zeta conferences played a more important role for building competences and relationships.

Zeta provides a flexible product architecture so that the innovating companies can reduce their resources; they easily can adjust and adapt components of the original product. For Alpha, it was critical that Zeta made the technical architecture more flexible so they could host their customers' solutions and thus make it much easier to maintain the software. The modular architecture of the CRM product allowed Alpha to change, add, and remove functionality without larger compatibility problems.

To attract new markets, Zeta supports the promotion of their partners' customized products. Alpha has secured that their products satisfy Zeta's perquisites and quality criteria for product promotion and has permission to promote their products on Zeta's home page, where Zeta's customers seek new products and product information. Promotion at conferences has been decisive for Alpha in finding new customers.

As ideas enter Zeta's open innovation environment, Zeta also provides inspiration to Alpha's product development early in the process. Alpha has been accepted as a member of Zeta's early-adopter program, which provides them in the research and the development stages with leading-edge information about new CRM product features and versions that are a source of inspiration for their own innovations. Alpha's participation in the beta tests has the same effect. Beyond improving the original product, Alpha's solutions ensure better utilization of the CRM product and contribute to its further sale to new markets. This is in line with Vanhaverbeke's (2006) claim that a focus on open innovation emerges often when companies such as Zeta try to promote and sell their products in new markets.

Zeta is relying and dependent on other companies' contributions to their product as they cannot cover all markets; this, in particular, is valid for niche markets with special needs. They continuously provide new versions of the original product as inspiration which their partners can customize and further develop.

Zeta works actively to identify companies interested in innovating their standard software. Beyond a significant effort to promote their partnership program with a 
minimal participation fee, Zeta helps minor, non-certified companies by providing free support and technical advice to develop solutions that will allow them to achieve partner certification. Zeta, Alpha, and Omega use this program and build an interorganizational network where they draw from each other's knowledge.

The formal relations in the interorganizational network are mostly made up by partners and less by customers. They have entered a number of partnerships and close alliances. Their first mutual links are created with the launch of Alpha's primary product. Alpha becomes a registered partner, which eases their customization of Zeta's CRM solution. This is beneficial for Zeta, which gets its product promoted through an increase of its business value. The partnership with Zeta is advantageous for Alpha, but initially far from as profitable as their relation to Omega. Their shared aims and strategic cooperation have been decisive for both partners' success on the CRM market through the creation of Alpha's first product.

Alpha's cooperation with Zeta on the CRM product exhibits a shared destiny based on both companies' mutual dependency (Harland 1996). Alpha's product development also leads to partnerships with two of Zeta's Danish CRM vendors. Alpha has entered these relationships to secure an increased sale of licenses for their products, which are distributed through these two partners. The partnerships are primarily a sales channel. In a similar way, Alpha has a relationship to the Zeta partner and U.S. distributor Delta, which is limited to their first product. Delta has been interested in the product and opens the US market for them.

Alpha forms a partnership with Gamma to satisfy the company's need for more competent staff who are sourced from Pakistan. The partnership forms a reciprocal dependency and can be considered as shared destiny where both partners have an interest in a mutual progress. Alpha finally merges with Omega, strengthening the organizations' positions in their individual networks. This is an important strategic reason for a merger (Harland 1996).

Alpha has, with Omega's support, created strong personal links to some Zeta employees. The company's sales manager, who has been a Zeta employee, has contributed and created a number of informal relations and commitments which Alpha carefully nurtures; for example, they are committed to providing technical help in situations where Zeta employees are not able to solve tasks themselves. This facilitates easier access to different kinds of information (Coleman 1988) and, for Alpha, their personal links to Zeta employees means that they no longer need to go through bureaucratic information channels, but can contact the relevant people when they need knowledge about certain things in the development process, thus building their core competencies about the CRM product.

Alpha's social structures with other organizations are strongly marked by the informal relations and personal bonds to Omega. Omega has been an important source of information and provided free advice to Alpha in its start-up phase concerning business and customer needs, and Alpha helped Omega to overcome technical problems with their CRM product. They thus strengthened their mutual trust to pool resources, knowledge, and competence. This has increased the social capital between the two organizations and decreased the need for formal rules and regulations in their cooperation.

Informal agreements typify social structures and it is difficult to identify the unwritten laws that define cooperation (Coleman 1988). Alpha's founders felt that 
they had to earn Zeta personnel's trust by rendering themselves visible by conference attendance. They also felt that they had to constantly meet Zeta employees' expectations. By satisfying these expectations, they are in a stronger position than other Zeta partners as they can better source technical information. These activities point to a social norm where a partner profits from the unwritten rule that its activity is rewarded in the form of easy access to product information.

Trusted relationships have been identified by Ågerfalk and Fitzgerald (2008) as a premise for open sourcing as a particular form of open innovation. A broad innovation network, as in our case, with many partners in many forms of relations carries the risk of superficial, insufficient trust; still, it is considered as having the best potential for innovation by Simard and West (2006). We find a network where the central partners evidently found the right level of trust.

In the relationship between Zeta and Alpha, we discover some examples for coopetive behavior. Zeta has defined the boundary between cooperation and competition, where opportunistic behavior might appear, in a formal, written contract that provides both sides with some certainty. Alpha is placed under these rules which determine the parts of the software they are allowed to customize and change in the original product. However, no formal agreement exists which describes what Alpha can customize to avoid Zeta copying their customized solution, a serious problem in open innovation environments (Graham and Mowery 2006). Only an informal agreement exists that Zeta try to avoid updating their software with identical solutions already developed by Alpha. Zeta's attempt to not immediately develop matching solutions is essential for Alpha's survival and creates some trust, which characterizes informal contracts (Ganguli 2007). Still, most of Alpha's products have a life span of 18 to 24 months so they are pushed to constantly develop new innovative customizations. Simultaneously, Zeta expects that Alpha will promote Zeta's products and contributes to Zeta's good reputation as a brand.

Opportunistic behavior and the right balance is thus a predicament for the relationship of Zeta and Alpha. Zeta does not always stay within the limits of their

Table 3. Characteristics of Open Innovation in the Case

\begin{tabular}{|l|l|}
\hline \multicolumn{2}{|l|}{ Open Innovation } \\
\hline Idea and Knowledge Flow & Coupled Process-outside-in/inside-out \\
\hline Knowledge Sharing Opportunities & $\begin{array}{l}\text { Developer communities conferences } \\
\text { Online developer forums }\end{array}$ \\
\hline Product Access and Flow & Access (e.g., through beta tests) \\
\hline Development Context & Flexible product architecture \\
\hline Partner Search & $\begin{array}{l}\text { Proactive search for partners } \\
\text { Technical counseling for non-certified partners }\end{array}$ \\
\hline Inducements & $\begin{array}{l}\text { Spin-off support } \\
\text { Cheap partner program } \\
\text { Partner solutions promotion on company page }\end{array}$ \\
\hline
\end{tabular}


announced changes when they update the original product. This creates a challenge as Alpha has to put extra effort into their customized solutions. Alpha is aware of this risk, but does not feel negative about the situation. They accept it as they are conscious of the power balance that exists when they customize a larger software producer's product and see this as a part of their living conditions. Alpha also has a dilemma: deficiencies in the CRM product are opportunities for new customized solutions, which are the basis for their business. Thus, at times they delay and limit their feedback about the product which Zeta asks for before they release a new version to customers. However, given the power balance, mutual opportunistic behavior will have more serious consequences for Alpha; thus, cooperation prevails. The results of our analysis are summarized in Tables 3 and 4.

Table 4. Findings Related to the Interorganizational Open Innovation Network in the Case

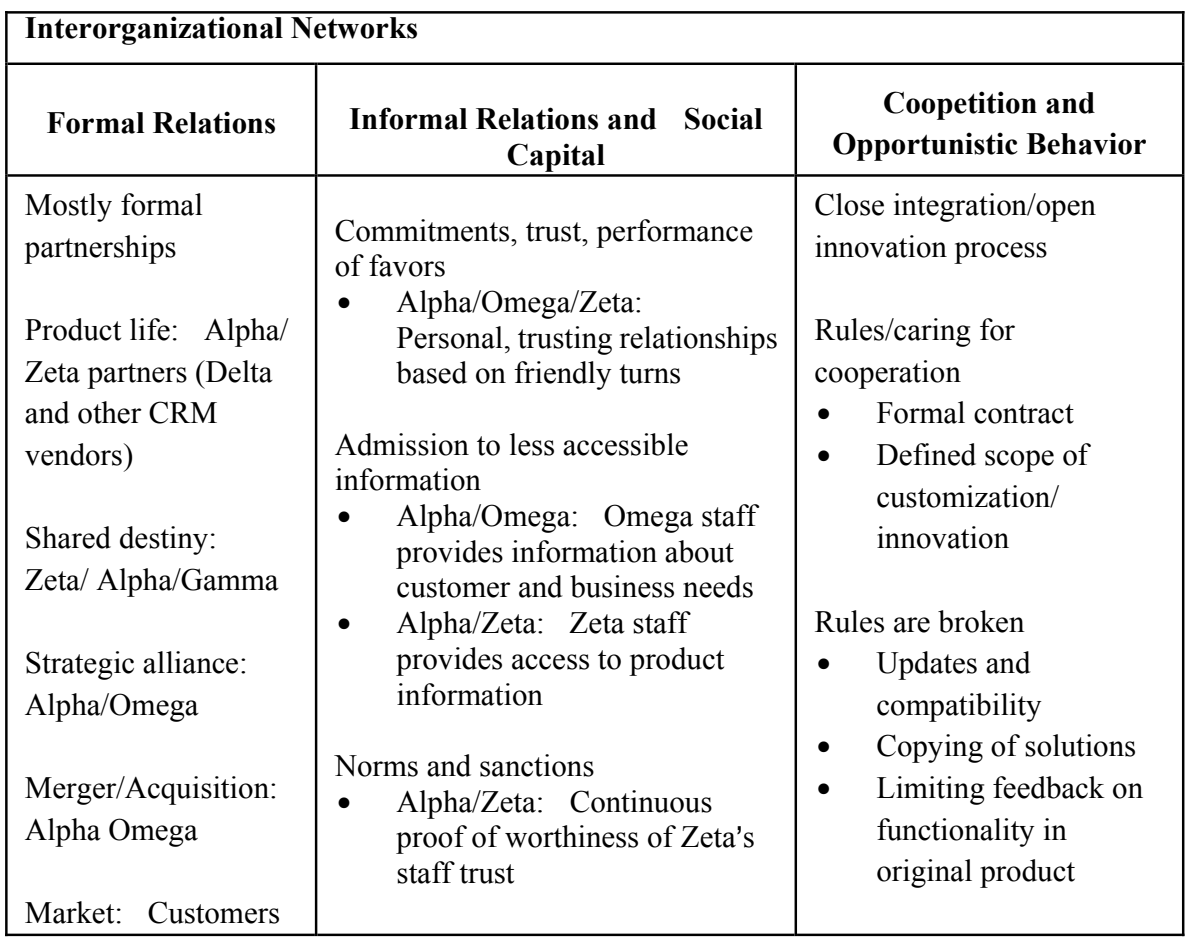

\section{Conclusions}

Most research on open innovation focuses on the firm (Grøtnes 2009) and research on interorganizational networks has either investigated regional innovation networks or network characteristics (Vanhaverbeke 2006; Vanhaverbeke and Cloodt 2006) from the perspective of one firm with the notable exception of Grøtnes (2009), who has studied the phenomenon in the neutral arena of standardization outside a firm. 
Despite the fact that results from single case studies are not generalizable, we contribute to the development of a theory of open IT innovation with a theoretical framework that integrates formally separate aspects of open innovation and interorganizational networks. We extend the literature on open innovation as an interorganizational phenomenon by broadening the view from one focal firm to the relations in a network of companies that mutually contribute to the innovations which occur in the different companies.

This research presents and analyzes an empirically grounded account of open innovation in the IT industry. We confirm and convincingly demonstrate that initiatives such as proactive search for new partners, providing occasions for developers to share knowledge and build communities, affording a suitable development context and an accommodating product architecture, as well as making inducements available in the form of financial support and promoting innovation partners (Chesbrough 2003; Simard and West 2006; Vanhaverbeke and Cloodt 2006; von Hippel 2005) are all schemes that successfully support open innovation undertakings.

We also substantiate that interorganizational networks have a significant influence on open innovation processes of the cooperating organizations (Vanhaverbeke 2006). Extending the investigation of the formal relations with the analysis of the informal relations is a contribution of our work. The network in our case primarily builds on formal partnerships with a number of different companies, but the informal relations are invaluable sources of knowledge. We thus recommend that companies involved in open innovation should support and nurture the informal relations of their employees both within and beyond organizational boundaries.

We find an extensive network with numerous collaborators in various relations. In line with Simard and West (2006), we corroborate this as one viable strategy in open IT innovation. We also find a network in which, despite formal contracts, opportunistic behavior occurs, influencing the case companies' interorganizational innovation processes. Because of the limited life of its products, the smaller company constantly seeks and collaborates with new partners which provide information about new business opportunities. This enables the company to continuously further develop their solution to be one step in front of the original software producer. A last lesson from our case is, therefore, to monitor the balance of formal contracts, informal relations, and opportunistic behavior, and to intervene, if necessary, to not jeopardize otherwise supportive open innovation initiatives.

As we have only studied one particular instance of an open innovation in an interorganizational network, further research is needed to confirm our results and understand and support other forms of the phenomenon.

\section{References}

Ågerfalk, P., Fitzgerald, B.: Outsourcing to an Unknown Workforce: Exploring Opensourcing as a Global Sourcing Strategy. MIS Quarterly 32(2), 385-410 (2008)

Chesbrough, H.: Open Innovation: A New Paradigm for Understanding Industrial Innovation. In: Chesbrough, H., Vanhaverbeke, W., West, J. (eds.) Open Innovation: Researching a New Paradigm, pp. 1-14. Oxford University Press, Oxford (2006)

Chesbrough, H.: Open Innovation: The New Imperative for Creating and Profiting from Technology. Harvard Business School Publishing, Boston (2003) 
Coleman, J.S.: Social Capital in the Creation of Human Capital. American J. of Sociology 94(6), 95-120 (1988)

Creswell, J.W.: Research Design-Qualitative, Quantitative and Mixed Methods Approaches. Sage Publications, Thousand Oaks (2003)

Dyer, J.H., Singh, H.: The Relational View: Cooperative Strategy and Sources of Interorganizational Competitive Advantage. Academy of Management Review 23, 660-679 (1998)

Eisenhardt, K.M.: Building Theories from Case Study Research. Academy of Management Review 14(4), 532-550 (1989)

Feller, J., Finnegan, P., Hayes, J., O’Reilly, P.: Institutionalizing Information Asymmetry: Governance Structures for Open Innovation. Information Technology \& People 22(4), 297-316 (2009)

Fincham, R.: Narratives of Success and Failure in Systems Development. Brit. J. of Management 13, 1-14 (2002)

Ganguli, S.: Coopetition Models in the Context of Modern Business. J. of Marketing Management 6, 4 (2007)

Gassmann, O., Enkel, E.: Towards a Theory of Open Innovation: Three Core Process Archetypes. In: Proceedings of The R\&D Management Conference, Lisbon, Portugal, July 6-9 (2004)

Germonprez, M., Hovorka, D.S., Collopy, F.: A Theory of Tailorable Technology Design. JAIS 8, art. 21, 351-367 (2007)

Graham, S.J.H., Mowery, D.C.: The Use of Intellectual Property in Software: Implications for Open Innovation. In: Chesbrough, H., Vanhaverbeke, W., West, J. (eds.) Open Innovation: Researching a New Paradigm, pp. 184-204. Oxford University Press, Oxford (2006)

Grøtnes, E.: Standardization as Open Innovation: Two Cases from the Mobile Industry. Information Technology \& People 22(4), 367-381 (2009)

Håkansson, H., Snehota, I.: Developing Relationships in Business Networks. Routledge, New York (1995)

Harland, C.M.: Supply Chain Management: Relationships, Chains and Networks. Brit. J. of Management 7, 63-80 (1996)

Kautz, K., Serrano, G.L., Barbolla, A.B., Corredera, J.R.C.: Guest Editorial Special Issue on Open IT-Based InnovationCMoving Towards Cooperative IT Transfer and Knowledge Diffusion. Information Technology \& People 22(4), 293-296 (2009)

Kuitunen, H., Jokinen, J.-P., Lassila, A., Mäkelä, M., Huurinainen, P., Maula, M., Ahokas, M., Kontio, J.: Finnish Software Product Business: Results from the National Software Industry Survey 2005. Centre of Expertise for Software Product Business, Tekes, Helsinki, Finland (2005)

Light, B.: The Maintenance Implications of the Customization of ERP Software. J. of Software Maintenance and Evolution: Research and Practice 13, 415-429 (2001)

Pollock, N., Williams, R., Procter, R.: Fitting Standard Software Packages to Non-Standard Organizations: The 'Biography' of an Enterprise-Wide System. Technology Analysis and Strategic Management 15(3), 317-332 (2003)

Sawyer, S.: Packaged Software: Implications of the Differences from Custom Approaches to Software Development. European J. of Information Systems 9, 47-58 (2000)

Scott, J.E., Kaindl, L.: Enhancing Functionality in Enterprise Software Package. Information and Management 7, 111-122 (2000)

Simard, C., West, J.: Knowledge Networks and the Geographic Locus of Innovation. In: Chesbrough, H., Vanhaverbeke, W., West, J. (eds.) Open Innovation: Researching a New Paradigm, pp. 220-240. Oxford University Press, Oxford (2006) 
Van de Ven, A.H.: Engaged Scholarship: A Guide for Organizational and Social Research. Oxford University Press, New York (2007)

Vanhaverbeke, W.: The Interorganizational Context of Open Innovation. In: Chesbrough, H., Vanhaverbeke, W., West, J. (eds.) Open Innovation: Researching a New Paradigm, pp. 205-219.

Oxford University Press, Oxford (2006)

Vanhaverbeke, W., Cloodt, M.: Open Innovation in Value Networks. In: Chesbrough, H., Vanhaverbeke, W., West, J. (eds.) Open Innovation: Researching a New Paradigm, pp. 258-284. Oxford University Press, Oxford (2006)

von Hippel, E.: Cooperation between Rivals: Informal Knowhow Trading. Research Policy 16(6), 291-302 (1987)

von Hippel, E.: Democratizing Innovation. MIT Press, Cambridge (2005)

Walsham, G.: Interpretive Case Studies in IS Research: Nature and Method. European J. of Information Systems 4, 74-81 (1995)

West, J., Gallagher, S.: Patterns of Open Innovation in Open Source Software. In: Chesbrough,

H., Vanhaverbeke, W., West, J. (eds.) Open Innovation: Researching a New Paradigm, pp. 82-108. Oxford University Press, Oxford (2006)

Williamson, O.E.: Comparative Economic Organization: The Analysis of Discrete Structural Alternatives. Administrative Science Quarterly 37(2), 269-296 (1991)

Yoo, Y., Lyytinen, K., Boland, R.J.: Distributed Innovation in Classes of Networks. In:

Proceedings of the 41st Annual Hawaii International Conference on System Sciences (2008)

\section{About the Authors}

Karlheinz Kautz is Professor in Systems Development and Software Engineering at the Department for Informatics at Copenhagen Business School. His research interests are in the diffusion and adoption of information technology innovations, systems development and system development methodologies for advanced application areas, the organizational impact of IT, knowledge management and software quality and process improvement. He has published widely in these areas. Karl is a founding member and past Chairman of the IFIP TC 8 WG 8.6 on the adoption and diffusion of IT.

Deborah Bunker is an associate professor in the Business Information Systems discipline at the University of Sydney. She is also president of the Australasian Association of IS and vice chair of IFIP Working Group 8.6 (Innovation, Diffusion, Transfer and Implementation of IS). She holds a Ph.D. in Information Systems Management. Her research interests are in IS philosophy, IS management, IS adoption and diffusion, and e-Commerce/e-Business. She has published widely in these areas.

Sameen M. Rab has been a student for the degree of Computer Science and Business Administration at Copenhagen Business School and has been a researcher for the project, which builds the basis for the research described here.

Michael Sinnet has been a student for the degree of Computer Science and Business Administration at Copenhagen Business School and has been a researcher for the project, which builds the basis for the research described here. 